International Journal of Pharmaceutics \& Pharmacology

EDW SER

Available Online: https://ijpp.edwiserinternational.com

\title{
Pharmacovigilance System in Bangladesh: A Regulatory Perspective
}

\section{Mohammad Wasif Khan*}

Senior Healthcare Professional, Shaheen Bagh, Jamia Nagar, New Delhi-110025, India

Article info

Received 01 March 2019

Revised 20 March 2019

Published 01 April 2019

*Corresponding author: Mohd. Wasif Khan, Senior Healthcare Professional, Shaheen Bagh, Jamia Nagar, New Delhi-110025, India; E-mail: kunwarwasif@gmail.com

\begin{abstract}
National pharmacovigilance centre of a country coordinates the overall activity of pharmacovigilance in collaboration with international regulatory authorities like WHO-UMC etc. The pharmacovigilance system establishment in public health has encouraging impact on health-care system improvement. To ensure the safety of medication system in Bangladesh, DGDA is leading from the front. In 2013, the Ministry of Health and Family Welfare, Bangladesh declared the DGDA as the National Pharmacovigilance Centre for Bangladesh, with the ADRM cell overseeing the centre's activities. The MOHFW also set up the independent ADR Advisory Committee to work in conjunction with the ADRM cell to provide technical guidance for implementing PV activities, evaluating ADE reports, and recommending regulatory decisions and actions to ensure medicine safety. The DGDA has developed guidelines and strategies to implement PV activities across the country in cooperation with all stakeholders. The salient features of current $P V$ regulations in Bangladesh are: An appropriate $P V$ system is in place within the company to conduct postmarketing surveillance activities; Suspected adverse reactions to drugs must be reported using the electronic version of the reporting form available in the fillable pdf on DGDA website and submitted to the ADRM cell; Submit PSURs and company-sponsored post-registration study reports to the ADRM cell on a quarterly basis; Respond promptly and fully to requests for risk/benefit information from the ADRM cell.
\end{abstract}

Keywords: Pharmacovigilance; WHO-UMC; DGDA; ADR; ADE; ADRM Cell; MOHFW; ADRAC; PSUR; RMP; Serious Adverse Event

\begin{abstract}
Abbreviations
ADE: Adverse Drug Event; ADR: Adverse Drug Reaction; ADRAC: Adverse Drug Reaction Advisory Committee; ADRM: Adverse Drug Reaction Monitoring; AEFI: Adverse Event following Immunization; BDNF: Bangladesh national drug formulary; DGDA: Directorate General of Drug Administration; HCP: Health-Care Professional; MAH: Marketing Authorization Holder; MOHFW: Ministry of Health and Family Welfare; MSH: Management
\end{abstract}

Science for Health; NPC: National Pharmacovigilance Centre; PSUR: Periodic Safety Update Reports; PV: Pharmacovigilance; SAE: Serious Adverse Event; SIAPS: Systems for Improved Access to Pharmaceuticals and Services; UMC: Uppsala Monitoring Centre; WHO: World Health Organization 


\section{Introduction}

Bangladesh is an underdeveloped country. According to the DGDA, we are now exporting wide range of products to more than 130 countries of the world. All major therapeutic class \& dosage forms along with high-tech products are included into it [1]. On contrary, country's major population has limited ideas about their health and medicines. This leads them face many serious health hazard (several drugs induced diseases like- vitals damage etc.) [2].

The scope of this article is to bring forth the pharmacovigilance $(\mathrm{PV})$ regulatory requirements in Bangladesh from the healthcare stakeholders. The article covers the Pharmacovigilance Regulatory requirements listed by the Health Authorities, gazettes and notification shared with the pharmaceutical industry/institutions. The author has conducted in depth research to identify the key Pharmacovigilance obligations in Bangladesh.

PV was introduced in Bangladesh in 1999 with the formation of an ADR monitoring cell by the then Directorate of Drug Administration and with the introduction of ADR reporting form which was distributed to approx. 8 medical college hospitals and seminar/workshops were organized. Unfortunately, the ADRM cell discontinued because of shortage of manpower \& required fund, and unwillingness of the health-care professional. However, due to a shortage of manpower and a lack of financial support, the program became dormant. Understanding the gravity of importance of drug safety, it was revived in 2013 when the Directorate General of Drug Administration (DGDA) established the Adverse Drug Reaction Monitoring (ADRM) cell with technical assistance from the USAID-funded SIAPS Program. The Ministry of Health and Family Welfare (MOHFW) declared the DGDA as the National Pharmacovigilance Centre (NPC) for Bangladesh, with the ADRM cell overseeing the center's activities. The MOHFW also revived Adverse Drug Reaction Advisory Committee (ADRAC) to work in conjunction with the ADRM cell to provide technical guidance for implementing PV activities; evaluate Adverse Drug Event (ADE) reports; and make recommendations for regulatory decisions to the DGDA, the country's licensing authority for drugs [3].

The Bangladesh National Pharmacovigilance Guidelines delivers a basic agenda for the one-time activity (establishment of the PV system) and its related routine activities in a widespread, efficient manner and serve as an outline for operationalizing the system. It details about the ways of effective collection, assessment, understanding and reporting of pharmaceutical products' safety data which is crucial in prevention of medication related issues. It is expected that the guidelines will ensure uniformity in the execution of safety and effectiveness monitoring activities of pharmaceuticals and other health products in Bangladesh.

This article covers a comprehensive assessment of the applicable pharmacovigilance regulatory obligations by regulatory Health authorities of Bangladesh [4].

\section{Definitions}

\section{Adverse Event}

An AE is defined as "Any untoward medical occurrence that may present during treatment with a pharmaceutical product, but which does not necessarily have a causal relationship with this treatment."

\section{Adverse Drug Reactions (ADR)}

ADR is defined by WHO, 1972 as "A response which is noxious and unintended, and which occurs at doses normally used in humans for the prophylaxis, diagnosis, or therapy of disease, or for the modification of physiological function"

\section{Causality assessment}

"The assessment of the likelihood that a drug was the causative agent of an observed adverse reaction." Causality assessment is usually made according established algorithms including WHO, Naranjo's scale.

\section{Individual Case Safety Report (ICSR)}

ICSR is source of data in pharmacovigilance. It is an AE report for an individual patient and details about other essential criteria to make an AE case valid.

\section{PSUR}

The PSUR is a stand-alone document intended to provide an update to regulatory authorities at defined time-points post-authorisation of the worldwide safety experience of a medicinal product.

\section{Serious Adverse Event (SAE)}

Any untoward medical occurrence that at any dose:

- results in death

- results in life-threatening condition 


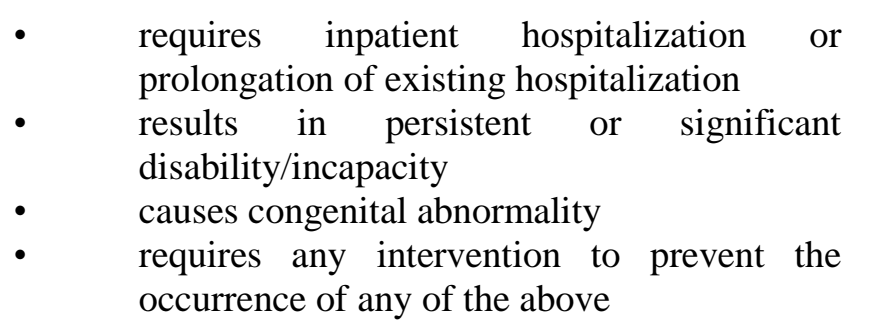

\section{Product quality problem}

A product quality problem relates to any product that is defective, deteriorated, or adulterated because of poor manufacturing practices, inadequate distribution and storage, poor labelling, or tampering. Counterfeit products would fall under this category.

\section{Regional requirements}

The regulatory authority issued an executive order to all institutes and companies in and around Dhaka to ensure their involvement in the required monitoring and reporting of their products' safety data.

Suspected adverse reactions to drugs - undocumented or unexpected reactions, serious adverse drug reactions, unexpected therapeutic effects, product quality problems, treatment failures, and medication errors must be reported using the electronic version of the reporting form available in the fillable pdf on DGDA website (www.dgda.gov.bd) and submitted to the ADRM cell by post, email (dgda.gov@gmail.com), or fax (+8802 9880854). In emergency cases or when forms are not readily available, reports can also be made to the ADRM cell by phone (+88029880803).

'Monitoring and engaging pharmaceutical manufacturers and other suppliers in the pharmaceutical industry to ensure that marketed drugs are of high quality and are safe for human consumption' is one of the main objectives of the national PV guidelines.

Once a product is registered and authorized to be on the market, MAHs are requested to continue to monitor the safety of their product through post-marketing surveillance. This surveillance combines the passive and active surveillance methods. It is initiated by the MAHs without direct participation of the DGDA, although MAHs should share all relevant information with the DGDA/ADRM cell when it becomes available [5-8]

\section{Companies/Institutions responsibilities}

- Inform the DGDA (ADRM cell) of any serious ADR arising from the use of their registered products immediately, and no later than one week, after the reporting of such adverse reactions

- $\quad$ Ensure that an appropriate PV system is in place within the company to accept responsibility and liability for its product on the market

- $\quad$ Submit periodic safety update reports (PSURs) and company-sponsored post-registration study reports to the ADRM cell on a quarterly basis

- Respond promptly and fully to requests for risk/benefit information from the ADRM cell [8]

\section{Responsibilities of companies/institutions regarding risk management}

MAHs for pharmaceutical products in Bangladesh are strongly encouraged to conduct post-marketing surveillance activities and to notify the ADRM cell of adverse events, particularly serious adverse events, and other product quality issues that come to their attention about their licensed product(s) in Bangladesh. Reports should be submitted with greater frequency during the first two years following authorization because less is known about the safety of newer products on the market.

It is recommended that MAHs follow international standards for serious adverse event notification and immediately report such events to the ADRM cell and no more than seven days after notification. MAHs are also requested to supply the ADRM cell with any additional information related to suspected serious adverse events that is needed for the purposes of causality assessment and the evaluation of benefits and risks associated with their product.

Based on international standards, manufacturers that are supplying medicines in Bangladesh; both national and multinational are generally encouraged to have PV structures, systems, and activities in place, including:

- A PV unit and/or designated staff person responsible for $\mathrm{PV}$ activities

- $\quad$ PV guidelines, standard operating procedures, and reporting forms

- $\quad$ Ongoing post-marketing surveillance activities, including post-marketing safety studies and risk minimization activities for high-risk medicines and products with unresolved safety profiles

- $\quad$ Risk management plans

- $\quad$ Periodic safety update reports

- A quality monitoring system that includes audits and inspections 
In all matters of PV, MAHs are expected to comply with the regulatory decisions of the DGDA that pertain to their products and to take appropriate action [8].

\section{Medicine promotion and advertising}

The DGDA regulates promotion and advertising. MAHs are expected to maintain complete and accurate information on their licensed products in Bangladesh and to update it as necessary. MAHs should also comply with good ethical practices and emerging regulations surrounding the promotion and advertising of their products in Bangladesh [8].

\section{Guidance for reporting adverse event following immunization}

AEFI Reporting Form, 2017 [8].

\section{Roles and responsibilities of ADRM cell}

- Adverse event notification forms/ reports collection

Adverse Drug Reaction (ADR) database Maintenance

- Signal generation: data analysis in safety database

- $\quad$ ADR review

- Narrative writing/summary preparation

- Submission of summary reports to ADRAC for regulatory recommendations

- Render support in implementation of the regulatory decisions made by DGDA and MOHFW as recommended by ADRAC through follow-up performance

- Collection of Medicines safety current information and circulate to health-care professionals

- Being point of contact for the WHO-UMC Program for International Drug Monitoring in sharing Bangladesh adverse event data

- $\quad$ Participation in active surveillances and other research studies on drug safety

- $\quad$ Setting of research priorities

- Implementation of training and education activities for health-care professionals involved in pharmacovigilance activities

- Maintenance of DGDA website, drug newsletters and bulletins and pharmaceutical journals in communicating medicine safety information

- Promotion of rational use of medicines and prevention of ADRs

- $\quad$ Bangladesh national drug formulary (BDNF) revision and maintenance $[8,9]$

\section{ADRM cell achievements}

- $\quad$ The approval of the modified suspected AE Reporting form in the meeting of Adverse Drug Reaction Advisory Committee (ADRAC)

- Preparation of activity flow chart \& organogram of ADRM cell

- Circulation of the directives to all drug manufacturers and importers regarding submission of their products' ADR monitoring reports after monitoring by own manpower/channel

- Selection of 20 hospital/healthcare provider institutes as primary point for reporting of ADR and one focal point from each organization and providence of training to this focal point on pharmacovigilance/ ADR reporting

- $\quad$ Launching of the pharmacovigilance program in association with MSH/SIAPS and pharmacovigilance system training to the officers of the DGDA

- Finalization of Guideline of National guideline for pharmacovigilance with the technical assistance from USAID, SIAPS/MSH

- Inclusion of pharmacovigilance activity in the present drug act

- Coordination in-between the activities of the DGDA \& Kalaazar/other diseases control program of DG Health Services

- $\quad$ Render support in inclusion of National Drug Monitoring Centre, DGDA, Bangladesh as associate member of WHO program for International Drug Monitoring in Uppsala, Sweden [8]

\section{Activity Specific Requirements}

\section{Pharmacovigilance system}

Institutions, Pharmaceutical Manufacturers and MAHs are responsible to ensure that an appropriate PV system is in place within the company to accept responsibility and liability for its product on the market.

\section{Regulatory Authority}

Based on international standards, manufacturers that are supplying medicines in Bangladesh - both national and multinational - are generally encouraged to have PV structures, systems, and activities in place, including:

- A PV unit and/or designated staff person responsible for $\mathrm{PV}$ activities

- $\quad$ PV guidelines, standard operating procedures, and reporting forms 
- A quality monitoring system that includes audits and inspections

In all matters of PV, MAHs are expected to comply with the regulatory decisions of the DGDA that pertain to their products and to take appropriate action [8].

Directorate General of Drug Administration

Aushad Bhavan, Mohakhali,

Dhaka-1212, Bangladesh

Tel: 8802 9880803, 9880864, 9880897, 9880924,

Fax: 88029880854 ,

E-mail: dgda.gov@gmail.com

Website: www.dgda.gov.bd

\section{ICSRs Reporting}

Companies should inform the DGDA (ADRM cell) of any serious ADR arising from the use of their registered products immediately, and no later than one week, after the reporting of such adverse reactions.

Suspected adverse reactions to drugs - undocumented or unexpected reactions, serious adverse drug reactions, unexpected therapeutic effects, product quality problems, treatment failures, and medication errors must be reported using the electronic version of the reporting form available in the fillable pdf on DGDA website (www.dgda.gov.bd) and submitted to the ADRM cell by post, email (dgda.gov@gmail.com), or fax (+8802 9880854). In emergency cases or when forms are not readily available, reports can also be made to the ADRM cell by phone ( +88029880803$)$.

It is recommended that MAHs follow international standards for serious adverse event notification and immediately report such events to the ADRM cell and no more than seven days after notification $[8,9]$.

\section{Reporting Forms}

- $\quad$ ADRM Reporting Form

- Instruction for Completing ADRM Reporting Form

- Online link for filling Suspected Adverse Event Reporting Form

- $\quad$ AEFI Reporting Form

(ADRM Reporting Form, DGDA, 2013), (Instruction for Completing ADRM Reporting Form, DGDA, 2013), (Online link for filling Suspected Adverse Event Reporting Form, DGDA, 2013), (National Guidelines on the Pharmacovigilance System in Bangladesh, DGDA, 2017).

\section{Periodic Regulatory Reporting}

Pharmaceutical Manufacturers and MAHs are responsible to submit periodic safety update reports (PSURs) and company-sponsored post-registration study reports to the ADRM cell on a quarterly basis and respond promptly and fully to requests for risk/benefit information from the ADRM cell.

MAHs in Bangladesh are strongly encouraged to conduct post-marketing surveillance activities and to submit reports with greater frequency during the first two years following authorization because less is known about the safety of newer products on the market.

MAHs are also requested to supply the ADRM cell with any additional information related to suspected serious adverse events that is needed for the purposes of causality assessment and the evaluation of benefits and risks associated with their product.

Manufacturers are generally encouraged to have PV systems including:

Ongoing post-marketing surveillance activities, including post-marketing safety studies and risk minimization activities for high-risk medicines and products with unresolved safety profiles

Risk management plans

Periodic safety update reports $[8,10]$

\section{Summary}

Pharmacovigilance ensures medication related safety issues handling and prevention and primarily deals with adverse drug reactions. With the outbreak of new diseases new medicines are developing worldwide so to prevent or lower the patient hazards, improvements in public health and precise evaluation and monitoring of drug safety are crucial. To achieve this goal, an efficient pharmacovigilance and ADR reporting system should be established in all countries. In Bangladesh, Directorate General of Drug Administration (DGDA) is playing a decisive role to ensure the safety of medication system.

In 2013, the Ministry of Health and Family Welfare, Bangladesh declared the DGDA as the National Pharmacovigilance Centre for Bangladesh, with the Adverse Drug Reaction Monitoring cell overseeing the centre's activities. The MOHFW also set up the independent Adverse Drug Reaction Advisory Committee to work in conjunction with the ADRM cell 
to provide technical guidance for implementing PV activities, evaluating adverse drug event (ADE) reports, and recommending regulatory decisions and actions to ensure medicine safety. The DGDA has developed guidelines and strategies to implement PV activities across the country in cooperation with all stakeholders. The salient features of current PV regulations in Bangladesh are-

MAHs are requested to ensure that an appropriate PV system is in place within the company to accept responsibility and liability for its product on the market continue to monitor the safety of their product through post-marketing surveillance.

MAHs for pharmaceutical products in Bangladesh are strongly encouraged to conduct post-marketing surveillance activities

Suspected adverse reactions to drugs must be reported using the electronic version of the reporting form available in the fillable pdf on DGDA website and submitted to the ADRM cell

Submit periodic safety update reports (PSURs) and company-sponsored post-registration study reports to the ADRM cell on a quarterly basis

Respond promptly and fully to requests for risk/benefit information from the ADRM cell.

\section{Conclusion}

Pharmacovigilance is very necessary for every country to maintain proper healthcare system and safety issues regarding treatment. The vision of DGDA is to ensure improvement of nationwide patient safety and wellbeing by reducing the risk of medicines used by patients and the general public. This challenge should be a common objective of all the major pharmacovigilance stakeholders (regulatory body, public including HCPs and pharmaceutical industries). Bangladesh has achieved the required initial steps in keeping patient safety at first and as a nation, they hope for a day will come when their National Drug Regulatory authority will be able to perform this noble activity like other developed countries.

\section{References}

1. Al-Mustansir M, Saha D, Paul S, et al. Studies on Pharmacovigilance in Bangladesh: Safety Issues. IJPTP 2013; 4: 613-621.

2. Jahan N, Hossain MA, Amran MS. Review on Pharmacovigilance Practice for Safety of Medication System in Bangladesh. Bangladesh Pharmaceutical J 2017; 20: 105-114.

3. Ahmed KS, Hossain MA. A Bangladesh perspective of Pharmacovigilance \& NDRA. Pharmabiz.com. 2014.

4. Pharmacovigilance Newsletter, DGDA, Ministry of Health \& Family Welfare Mohakhali, Dhaka, Bangladesh, $\quad 1$ : 2016. (http://www.dgda.gov.bd/index.php/newsletter/164 -pharmacovigillance-newsletter-issue-1)

5. DGDA, Ministry of Health \& Family Welfare Mohakhali, Dhaka, Bangladesh, 2013. (http://www.dgda.gov.bd/index.php/2013-03-3104-35-57/adrm-reporting-form)

6. DGDA, Ministry of Health \& Family Welfare Mohakhali, Dhaka, Bangladesh, 2013. (http://www.dgda.gov.bd/index.php/2013-03-3104-35-57/instructions-for-completing-adereporting-form)

7. DGDA, Ministry of Health \& Family Welfare Mohakhali, Dhaka, Bangladesh, 2013. (http://www.dgda.gov.bd/index.php/2013-03-3104-35-57/adrm-entry-form)

8. DGDA, Ministry of Health \& Family Welfare, Mohakhali, Dhaka, Bangladesh. National Guidelines on the Pharmacovigilance System in Bangladesh, 2017. (http://www.dgda.gov.bd/index.php/nationalguidelines-on-the-pharmacovigilance-system-inbangladesh)

9. Mohiuddin AK. Pharmacovigilance and Managing ADRS in Bangladesh: Eccentric or Non-existent? IJHP 2019: 4: 25.

10. Helali AM, Iqbal MJ, Islam MZ, et al. The evolving role of pharmacovigilance and drug safety: The way forward for Bangladesh. Int J Pharm 2014; 6: 3137.

This manuscript was peer-reviewed

Mode of Review: Single-blinded

Academic Editor: Dr. MA Jahangir

Copyright: (92019 Khan MW. This article is distributed under the terms of the Creative Commons Attribution 4.0 International License (http://creativecommons.org/licenses/by/4.0/), which permits unrestricted use, distribution, and reproduction in any medium, provided you give appropriate credit to the original author(s) and the source, provide a link to the Creative Commons license, and indicate if changes were made. 